\title{
Efficacy and Safety of Prucalopride in Patients with Chronic Noncancer Pain Suffering from Opioid-Induced Constipation
}

\author{
Cornelius E. J. Sloots • An Rykx • Marina Cools • \\ Rene Kerstens • Martine De Pauw
}

Received: 16 November 2009/Accepted: 25 March 2010/Published online: 30 April 2010

(C) The Author(s) 2010. This article is published with open access at Springerlink.com

\begin{abstract}
Background Opioid-induced constipation (OIC) has negative effects on quality of life (QOL). Prucalopride is a new, selective 5- $\mathrm{HT}_{4}$ agonist and enterokinetic with strong clinical data in chronic constipation. This study investigated the efficacy, safety, and tolerability of prucalopride in patients with noncancer pain and OIC.

Methods A phase II, double-blind, placebo-controlled study of 196 patients randomized to placebo $(n=66)$, prucalopride $2 \mathrm{mg}(n=66)$ or $4 \mathrm{mg} \quad(n=64)$, for 4 weeks, was carried out. The primary endpoint was the proportion of patients with increase from baseline of $\geq 1$ spontaneous complete bowel movement (SCBM)/week. Secondary endpoints [proportion of patients with $\geq 3$ SCBM/week, weekly frequency of (SC)BM, severity of constipation, and efficacy of treatment], adverse events (AEs), and safety parameters were also monitored.

Results More patients had an increase from baseline of $\geq 1$ SCBM per week (weeks 1-4) in the prucalopride groups [35.9\% (2 mg) and 40.3\% (4 mg)] versus placebo (23.4\%), reaching statistical significance in week 1 . Over weeks 1-4, more patients in the prucalopride groups
\end{abstract}

These results have been presented in part at Digestive Disease Week 2008 and were published as an abstract: Moulin et al.

Gastroenterology 2008; 134:A92.

C. E. J. Sloots $(\square)$

Department of Pediatric Surgery, Erasmus Medical Center, P.O. Box 2040, 3000 CA Rotterdam, The Netherlands

e-mail: c.sloots@erasmusmc.nl

A. Rykx · M. Cools $\cdot$ R. Kerstens $\cdot$ M. De Pauw

Movetis N.V., Turnhout, Belgium achieved an average of $\geq 3$ SBM per week versus placebo (60.7\% and $69.0 \%$ versus $43.3 \%$ ), reaching significance at week 1. Prucalopride $4 \mathrm{mg}$ significantly improved patient-rated severity of constipation and effectiveness of treatment versus placebo. Patient Assessment of Constipation-Symptom (PAC-SYM) total scores and Patient Assessment of Constipation-Quality of Life (PAC-QOL) total and satisfaction subscale scores were improved. The most common AEs were abdominal pain and nausea. There were no clinically relevant differences between groups in vital signs, laboratory measures or electrocardiogram parameters.

Conclusion In this population with OIC, prucalopride improved bowel function and was safe and well tolerated.

Keywords Opioid-induced bowel dysfunction . Prucalopride $\cdot$ Safety $\cdot$ Efficacy $\cdot$ Constipation

\section{Introduction}

It has been estimated that globally around 365 million prescriptions were written for opioids in 2005 [1, 2]. In addition to their intended therapeutic (analgesic) effect, opioids often lead to opioid-induced bowel dysfunction (OBD), which can have a significant adverse effect on patients' quality of life (QOL) that persists for as long as opioid therapy is administered [3, 4]. By activating opioid receptors in the gastrointestinal (GI) tract, opioids inhibit the normal release of excitatory and inhibitory neurotransmitters, thereby interrupting the rhythmic contractions required for normal intestinal motility and reducing mucosal secretions [5, 6]. Normal bowel function is inhibited [7], and constipation is therefore a common side-effect of opioid treatment, along with 
decreased gastric emptying, abdominal cramping, spasm, bloating, delayed GI transit, and the formation of hard, dry stools. This can cause straining, painful defecation, incomplete evacuation, and a sensation of bowel obstruction [7-10].

Estimates of the frequency of constipation range from $15 \%$ to $90 \%$ in patients receiving opioids for noncancer pain $[9,11,12]$. Patients rarely develop tolerance to the constipation-related effects of opioids, and effects tend to increase with increasing doses of opioid [13]. Some patients receiving long-term opioid treatment for pain would rather endure their pain than the constipation that opioids may cause [4].

To promote bowel movements in patients with OBD, laxatives are most commonly used. However, they do not target the underlying cause and results are therefore unpredictable, and their clinical efficacy can be difficult to assess due to the lack of high-quality placebo-controlled trials. Stool softeners, stimulant laxatives, osmotic agents, and lubricants are all prescribed but are not effective in all patients [3, 4].

Prucalopride is the first compound of a new class of highly selective 5- $\mathrm{HT}_{4}$ agonists with strong enterokinetic activity [14-16]. A comprehensive phase III dataset supports its efficacy in chronic constipation patients for whom laxatives do not provide adequate relief.

In preclinical studies it has been shown that prucalopride can induce giant migrating contractions (GMCs), stimulate proximal colonic motility, enhance gastro-pyloro-duodenal motility, and accelerate delayed gastric emptying [17]. Phase II studies in patients with chronic constipation have demonstrated that oral prucalopride treatment at a dose of $0.5-4 \mathrm{mg}$ increases stool frequency and decreases stool consistency [14, 18-21]. Phase III studies have shown that prucalopride can normalize bowel habit [as defined by a mean of $\geq 3$ spontaneous complete bowel movements (SCBM) per week] in $\sim 30 \%$ of patients $(2 \mathrm{mg}$ dose, versus $12 \%$ with placebo, $P<0.001)$ and increase the proportion of patients with an increase of $\geq 1$ SCBM per week ( $47 \%$ with $2 \mathrm{mg}$ versus $26 \%$ with placebo, $P<0.001)$ [22-24]. Prucalopride treatment also results in improvements in other associated symptoms and QOL [22-24]. Prucalopride has been well tolerated in all patient groups studied to date during treatment and in long-term follow-up [22-26]. Prucalopride has recently been approved by the EMA for symptomatic treatment of chronic constipation (CC) in women for whom laxatives provide inadequate relief. The objective of this phase II study is to evaluate the efficacy, the effects on QOL, and the safety and tolerability of prucalopride in patients with noncancer pain suffering from OIC.

\section{Methods}

Design

This was a multicenter, phase II, randomized, doubleblind, placebo-controlled study conducted in eight countries and involving 60 study centers ranging from hospitals to research clinics where patients were being treated for noncancer pain. Treatment duration was 4 weeks. The trial was designed by Janssen Research Foundation and ran from March 1999 to 2000. The study was conducted in accordance with the principles of the Declaration of Helsinki and the principles of good clinical practice (GCP), and all participants gave written informed consent before they were admitted to the trial. The final study protocol and amendments were approved by independent Ethics Committees or the appropriately constituted Institutional Review Boards (IRBs).

The clinical development program for prucalopride was stopped in 2003 by Janssen Research foundation after an internal strategic prioritization exercise, and was transferred to Movetis N.V. in 2007 as part of a portfolio of GI compounds that is now being further developed. At this time, the data from this randomized, controlled trial investigating the effect of prucalopride on OIC were reviewed. It was decided that these data were of general interest and should be offered for publication.

\section{Inclusion and Exclusion Criteria}

Male and female (non-pregnant and non-breastfeeding) outpatients of at least 18 years of age were eligible to enter the 2-week run-in period ( 3 weeks if the patient was using agents that influenced bowel habit) if they had OIC clearly secondary to chronic daily opioid use, starting at least 2 weeks prior to the first visit and expected to last for at least 6 further weeks, expected to stay on a minimum daily dose of the same opioid for at least 6 weeks, and with no history of chronic constipation prior to commencement of opioid therapy. Patients were recruited with chronic pain of any etiology (except cancer) that required daily maintenance treatment with opioids. Patients taking laxatives were required to stop their use during run-in and switch to the rescue medication [Dulcolax ${ }^{\circledR}$ (bisacodyl) and/or enemas].

Patients were eligible for randomization if, during the run-in period, patient-completed diary of bowel movements recorded a weekly average of two or fewer spontaneous bowel movements that resulted in a feeling of complete evacuation (SCBM), if they answered positively on the question "if they were bordered by their constipation?" and if they had stopped laxative treatment and switched to bisacodyl and enemas. A spontaneous bowel 
movement (SBM) is a bowel movement not preceded within a period of $24 \mathrm{~h}$ by the intake of a laxative agent. Patients were excluded if their constipation was thought to be caused by factors other than opioid therapy, such as other drugs, endocrine, metabolic, neurological, or other serious illnesses.

\section{Treatments}

Patients were allocated to one of three groups (according to a randomization code) to take placebo, prucalopride $2 \mathrm{mg}$, or prucalopride $4 \mathrm{mg}$ orally once daily (before breakfast) for 4 weeks. Balancing ensured that equal numbers of patients entered each treatment group. Patients and investigators were blinded to treatment received.

Patients had to remain on a stable minimal daily maintenance dose of opioid for the duration of the trial, and a change in the dose or combination with another opioid was only allowed for management of breakthrough pain. Combination of the opioid with a nonnarcotic analgesic was allowed.

Agents that might influence bowel habit, such as anticholinergics, spasmolytics, and prokinetics, were discontinued 21 days before the start of the study and throughout the treatment period. Antidepressant treatment was allowed if the patient had been taking a stable dose of antidepressant for at least 4 weeks prior to inclusion in the trial.

During the study, laxatives were not allowed, apart from a single dose of $10 \mathrm{mg}$ bisacodyl which was allowed as rescue medication if the patient had not had a bowel movement for $48 \mathrm{~h}$. A further increase in the dose was allowed if a single dose was insufficient, and after this an enema could be administered. No bisacodyl or enema was allowed within $24 \mathrm{~h}$ of (before or after) the first intake of trial medication.

\section{Assessments}

\section{Efficacy Assessments}

Diary data and questionnaires were collected during the run-in and the treatment periods. Bowel movement data (time, consistency, sensation of complete evacuation, straining) were recorded in the diary. Run-in data provided baseline values for treatment comparisons. A SBM is a BM not preceded within a period of $24 \mathrm{~h}$ by the intake of a laxative agent. A SCBM is a SBM that resulted in a feeling of complete evacuation.

The primary endpoint was the proportion of patients with an average increase from baseline of $\geq 1$ SCBM per week during the 4-week study period. Secondary endpoints included the proportion of patients having, on average, $\geq 3$ SCBM per week during the 4-week trial period and the average weekly frequency of SCBMs, SBMs, and all BMs. All SCBM and BM parameters were assessed at each individual week and over the total 4-week duration, based on diary data recorded by patients.

Patients' global assessment of severity of constipation and efficacy of treatment were determined as follows. For severity of constipation, each patient was asked to record his/her severity of constipation over the past 2 weeks, on the following five-point scale: absent (0), mild (1), moderate (2), severe (3), very severe (4). This questionnaire was completed at baseline, week 2 , and week 4 or at endpoint. For assessment of treatment efficacy, each patient was asked to rate his/her efficacy of treatment using the following five-point scale: not at all effective (0), a little bit effective (1), moderately effective (2), quite a bit effective (3), extremely effective (4). This questionnaire was completed at week 2 and at week 4.

The Patient Assessment of Constipation-Symptom (PAC-SYM) and the Patient Assessment of ConstipationQuality of Life (PAC-QOL) questionnaires were also used. Higher scores reflect greater severity of symptoms and poorer QOL, respectively.

The PAC-SYM was completed at baseline, week 2, and week 4, based on how patients felt in the previous 2 weeks, and PAC-QOL was completed at baseline and at week 4. The PAC-SYM is a validated questionnaire that is used to assess the severity of 12 constipation-related symptoms grouped into three subscales: stool symptoms, abdominal symptoms, and rectal symptoms [27]; it has also been validated for use in opioid-induced constipation [28]. Patients rated the severity of each symptom on a five-point scale from 0 (absent) to 4 (very severe), and scores are reported as an average total score or subscale score. The PAC-QOL is a validated questionnaire which assesses 28 items grouped into four subscales: physical discomfort, psychosocial discomfort, worries and concerns, and satisfaction [29]. As with the PAC-SYM questionnaire, items are rated on a five-point scale from 0 to 4 , and scores are reported as an average total score or subscale score.

\section{Safety Assessments}

Adverse events (AEs) were reported from the first visit to the end of the trial. At the first visit, a medical and surgical history was taken; physical examination, laboratory evaluation, and ECGs were performed at first and last visit (or discontinuation); and vital signs were recorded at each visit.

Twelve-lead ECGs were taken at the start of the study and after 4 weeks of treatment. ECGs were analyzed centrally, and the intervals RR, PR, QRS, and QT were measured manually with electronic calipers. QT interval was corrected for heart rate according to Bazett (QTcB) and 
Fridericia (QTcF) formulae. All ECG measurements and interpretations were validated by a cardiologist experienced in reading ECGs.

\section{Statistical Analysis and Sample Size}

The sample size estimation was based on assumed response rates for the primary endpoint $(25 \%$ for placebo and $55 \%$ for prucalopride doses), $80 \%$ power, and significance level of $2.5 \%$ (corrected for two comparisons). This resulted in a sample size of 48 patients per group, which was then corrected to account for $20 \%$ of patients with expected insufficient diary data. Therefore, the required sample size was 60 patients per group (180 patients in total).

All statistical tests were interpreted at the 5\% significance level (two-sided).

Intent-to-treat analysis and two-way analysis of variance (ANOVA) was used for continuous variables including factors for treatment, baseline, and country. The van Elteren test was used to control for country for betweentreatment-group comparisons of ordinal categorical variables, and the Cochran-Mantel-Haenszel test for nominal categorical variables.

Holm's step-down procedure was used for interpretation of multiple pairwise comparisons of ordinal variables, and Dunnett's test was used on least-square means for continuous variables.

\section{Results}

One hundred ninety-six patients under the care of 54 investigators were randomized: 66 to placebo, 66 to prucalopride $2 \mathrm{mg}$, and 64 to prucalopride $4 \mathrm{mg}$. This group formed the safety set. The population, the primary population for efficacy and QOL analyses, comprised 190 patients. The six patients (all from the same study center) not included in the population were excluded for reasons related to good clinical practice. A total of 29 patients withdrew before study completion (Fig. 1).

The median age of patients was 50 years (range 21-86 years), and $61.2 \%$ of the patients were female. There were no statistically significant differences between the groups in terms of age, race or weight (Table 1).

Table 1 also summarizes the opioid therapy taken by patients during the trial; the majority of patients were taking morphine $(67.9 \%)$, and two or more opioids were used by a number of patients for control of breakthrough pain. Opioids for maintenance pain were taken for an average of 6.7-6.9 days per week during the run-in as well as during weeks 1-4, with no significant difference between treatment groups.

Patients had an average of $0.3-0.5 \mathrm{SCBM} /$ week and 1.5-2.4 SBM/week at baseline (Table 2). The most frequent patient complaints related to constipation were difficulty in defecation (36-45\%), straining (33-39\%), and hard stools $(27-39 \%)$. Patients could indicate more than one complaint.
Fig. 1 Disposition of patients throughout the study

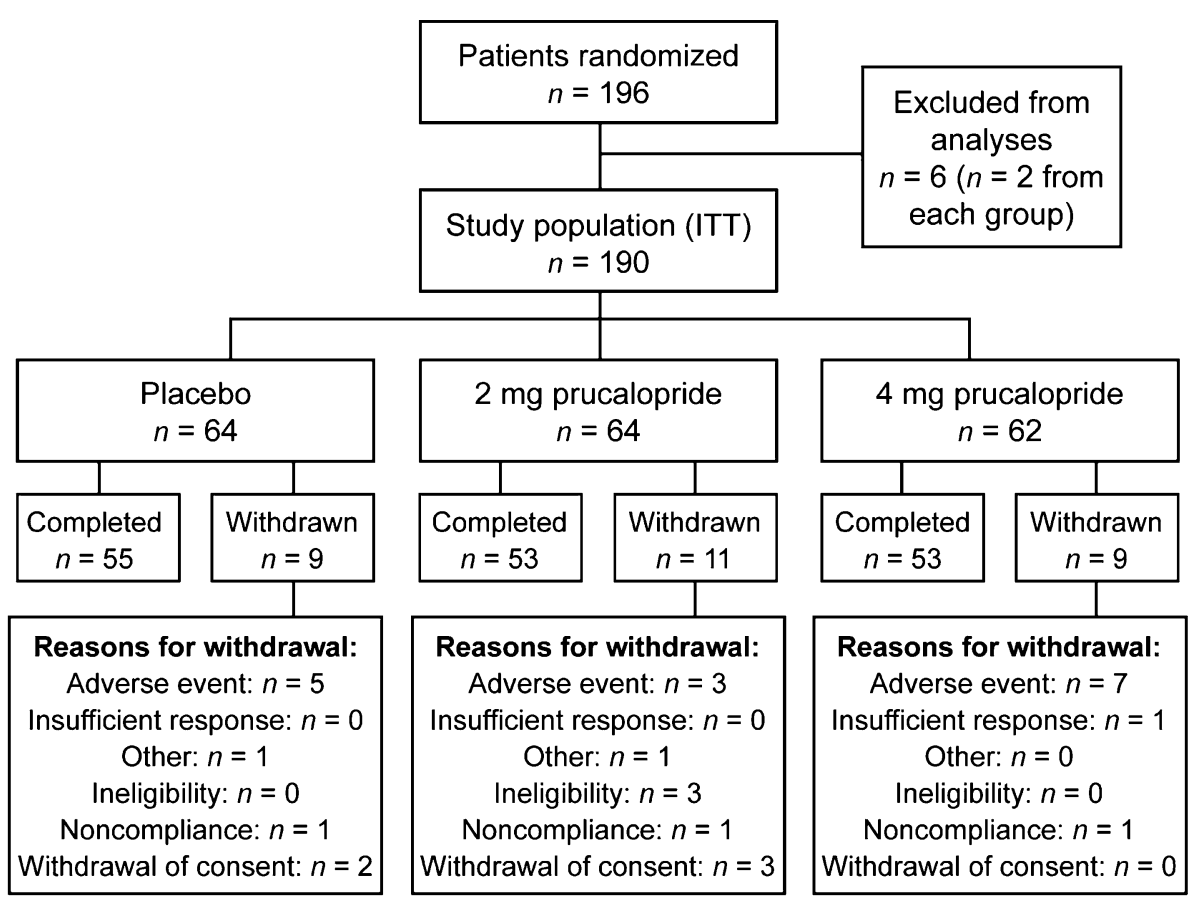


Table 1 Characteristics of study population and opioid therapy taken during the trial

\begin{tabular}{lccc}
\hline & $\begin{array}{l}\text { Placebo } \\
(n=66)\end{array}$ & $\begin{array}{l}\text { Prucalopride } \\
2 \mathrm{mg}(n=66)\end{array}$ & $\begin{array}{l}\text { Prucalopride } \\
4 \mathrm{mg}(n=64)\end{array}$ \\
\hline $\begin{array}{l}\text { Characteristic } \\
\text { Median (range) } \\
\text { age, years }\end{array}$ & $49(24-80)$ & $51(29-86)$ & $50.5(21-81)$ \\
Caucasian, $n(\%)$ & $66(100)$ & $65(98.5)$ & $63(98.4)$ \\
$\begin{array}{l}\text { Median (range) } \\
\text { weight, kg }\end{array}$ & $70(44-117)$ & $73.5(45-117)$ & $75(42-103)$ \\
Opioids taken, $n(\%)$ & & \\
Codeine & $9(13.6)$ & $11(16.7)$ & $4(6.3)$ \\
Dihydrocodeine & $1(1.5)$ & $0(0.0)$ & $1(1.6)$ \\
Fentanyl & $11(16.7)$ & $12(18.2)$ & $5(7.8)$ \\
Hydromorphone & $0(0.0)$ & $3(4.5)$ & $7(10.9)$ \\
Morphine & $48(72.7)$ & $45(68.2)$ & $40(62.5)$ \\
Other & $6(9.1)$ & $10(15.2)$ & $14(21.9)$ \\
Oxycodone & $8(12.1)$ & $4(6.1)$ & $4(6.3)$ \\
\hline
\end{tabular}

Table 2 Frequency and changes in frequency of bowel movements

\begin{tabular}{|c|c|c|c|}
\hline Variable & Placebo & Prucalopride $2 \mathrm{mg}$ & Prucalopride $4 \mathrm{mg}$ \\
\hline \multicolumn{4}{|c|}{ Mean (SE) average weekly frequency of $\mathrm{SCBM}^{\mathrm{a}}$} \\
\hline Baseline & $0.3(0.07)$ & $0.5(0.11)$ & $0.3(0.08)$ \\
\hline Week 1 & $0.6(0.14)$ & $1.6(0.28)$ & $1.8(0.35)^{* *}$ \\
\hline Weeks $1-4$ & $0.9(0.17)$ & $1.6(0.25)$ & $1.4(0.23)$ \\
\hline \multicolumn{4}{|c|}{ Mean (SE) average weekly frequency of $\mathrm{SBM}^{\mathrm{b}}$} \\
\hline Baseline & $1.5(0.23)$ & $2.3(0.23)$ & $2.4(0.36)$ \\
\hline Week 1 & $2.9(0.34)$ & $4.5(0.40)$ & $6.0(0.62)^{* * *}$ \\
\hline Weeks $1-4$ & $3.0(0.34)$ & $4.5(0.42)$ & $4.9(0.60)^{*}$ \\
\hline \multicolumn{4}{|c|}{$\begin{array}{l}\text { Proportion of patients with an average increase of } \geq 1 \text { BM per week, } n \\
(\%)^{\mathrm{c}}\end{array}$} \\
\hline Week 1 & $22(34.4)$ & $28(43.8)$ & $37(61.7)^{* *}$ \\
\hline Weeks $1-4$ & $15(25.0)$ & $22(36.1)$ & $24(41.4)$ \\
\hline \multicolumn{4}{|c|}{$\begin{array}{l}\text { Proportion of patients with an average increase of } \geq 1 \text { SBM per week, } \\
n(\%)^{\mathrm{d}}\end{array}$} \\
\hline Week 1 & $28(43.8)$ & $37(57.8)$ & $45(75.0) * * *$ \\
\hline Weeks $1-4$ & $29(48.3)$ & $33(54.1)$ & $37(63.8)$ \\
\hline
\end{tabular}

\section{Efficacy}

The percentage of patients with an increase from baseline of $\geq 1$ SCBM per week averaged over 4 weeks was higher in the prucalopride groups compared with placebo, reaching statistical significance in the first week of treatment for both 2 and $4 \mathrm{mg}$ prucalopride versus placebo $(P=0.021$ and 0.002, respectively; Fig. 2).

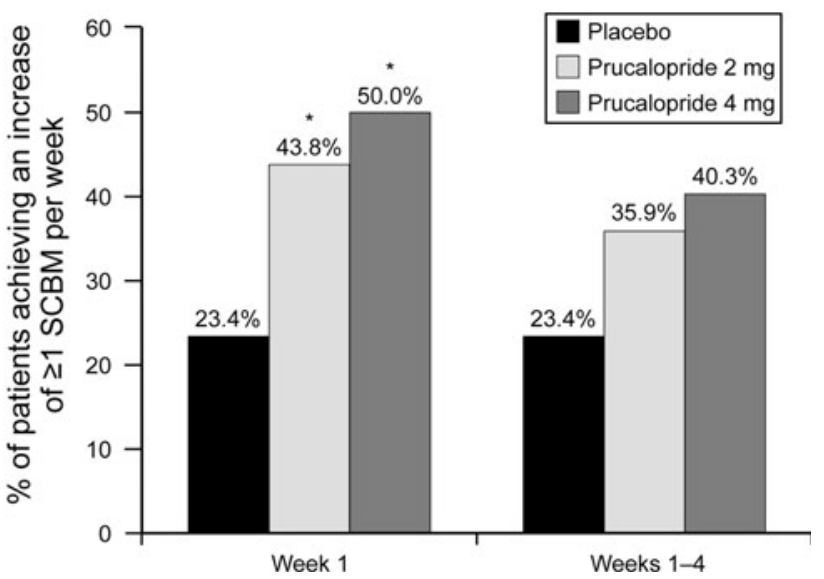

Fig. 2 Effect of prucalopride on the primary efficacy endpoint. Proportion of patients with an increase of $\geq 1$ SCBM per week from baseline, at week 1 and averaged over weeks $1-4$, in patients treated with prucalopride ( 2 and $4 \mathrm{mg}$ ) and placebo. $* P<0.021$ and $P=0.002$, respectively, versus placebo

Averaged over weeks $1-4$, more patients in the prucalopride 2 and $4 \mathrm{mg}$ groups had $\geq 3$ SCBM per week compared with the placebo group $(23.4 \%$ and $12.9 \%$ versus $9.4 \%)$, reaching significance at week $1(25 \%$ and $23.3 \%$ versus $3.1 \%, P \leq 0.001)$.

Over 4 weeks of treatment, more patients in the prucalopride 2 and $4 \mathrm{mg}$ groups had on average $\geq 3 \mathrm{SBM}$ per week compared with the placebo group $(60.7 \%$ and $69.0 \%$ versus $43.3 \%$, respectively), which was significant for the $4 \mathrm{mg}$ prucalopride group $(P=0.01)$. After 1 week of treatment, $67.2 \%$ of the $2 \mathrm{mg}$ and $81.7 \%$ of the $4 \mathrm{mg}$ prucalopride group were responders for this parameter compared with $46.9 \%$ of placebo-treated patients $(P=0.034$ and $P<0.001$ for 2 and $4 \mathrm{mg}$ prucalopride versus placebo, respectively). Note that at run-in, $29.7 \%$, $32.3 \%$, and $19.0 \%$ of patients already had $\geq 3$ SBM per week in the $2 \mathrm{mg}$ prucalopride, $4 \mathrm{mg}$ prucalopride, and placebo group, respectively.

Average weekly frequencies of SCBM and SBM were significantly higher in the prucalopride treatment groups compared with placebo (Table 2), in the $4 \mathrm{mg}$ prucalopride group in week 1 for both frequencies, and additionally over the 4-week treatment for the SBM frequency.

The proportion of patients with an increase of $\geq 1$ SBM per week, or $\geq 1 \mathrm{BM}$ per week were all higher in the prucalopride treatment groups than in the placebo group, with statistically significant differences after the first week of treatment for the $4 \mathrm{mg}$ prucalopride group (Table 2).

When compared with placebo, the mean decrease in the patient-assessed severity of constipation (rated on the fivepoint scale from "absent $=0$ " to "very severe $=4$ ") was significantly greater for the prucalopride $4 \mathrm{mg}$ group 
Table 3 Patient-assessed severity of constipation and treatment efficacy

\begin{tabular}{|c|c|c|c|}
\hline Variable & Placebo & $\begin{array}{l}\text { Prucalopride } \\
2 \mathrm{mg}\end{array}$ & $\begin{array}{l}\text { Prucalopride } \\
4 \mathrm{mg}\end{array}$ \\
\hline \multicolumn{4}{|c|}{$\begin{array}{l}\text { Patient-assessed severity of constipation (five-point rating scale from } \\
\text { "absent }=0 " \text { to "very severe }=4 " \text { ) }\end{array}$} \\
\hline \multicolumn{4}{|l|}{ Baseline } \\
\hline Rating & 2.75 & 2.59 & 2.71 \\
\hline \multicolumn{4}{|l|}{ Week 2} \\
\hline Rating & 2.6 & 2.31 & 2.02 \\
\hline Mean change from baseline & -0.12 & -0.32 & $-0.68 * *$ \\
\hline \multicolumn{4}{|l|}{ Endpoint $^{\mathrm{a}}$} \\
\hline Rating & 2.45 & 2.22 & 1.98 \\
\hline Mean change from baseline & -0.27 & -0.38 & $-0.71 *$ \\
\hline \multicolumn{4}{|c|}{ Patient-assessed efficacy of treatment, $n(\%)$} \\
\hline \multicolumn{4}{|l|}{ Week 2} \\
\hline $\begin{array}{l}\text { Not at all or a little bit } \\
\text { effective }\end{array}$ & $\begin{array}{l}39 \\
(67.3)\end{array}$ & $35(56.5)$ & $25(40.4)$ \\
\hline Moderately effective & $\begin{array}{l}11 \\
(19.0)\end{array}$ & $13(21)$ & $12(21)$ \\
\hline $\begin{array}{l}\text { Quite or extremely } \\
\text { effective }\end{array}$ & $8(13.7)$ & $14(22.5)^{\dagger}$ & $22(38.6)^{\dagger \dagger \dagger}$ \\
\hline \multicolumn{4}{|l|}{ Endpoint $^{\mathrm{a}}$} \\
\hline $\begin{array}{l}\text { Not at all or little bit } \\
\text { effective }\end{array}$ & $\begin{array}{l}37 \\
(61.7)\end{array}$ & $31(49.2)$ & $24(41.4)$ \\
\hline Moderately effective & $\begin{array}{l}13 \\
(21.7)\end{array}$ & $17(27)$ & $12(20.7)$ \\
\hline $\begin{array}{l}\text { Quite or extremely } \\
\text { effective }\end{array}$ & $\begin{array}{l}10 \\
(16.6)\end{array}$ & $15(23.8)$ & $22(37.9)^{\dagger \dagger}$ \\
\hline
\end{tabular}

$* P \leq 0.05, * * P \leq 0.01$, pairwise comparison of change from baseline versus placebo (Dunnett's procedure)

${ }^{\dagger} P \leq 0.05,{ }^{\dagger} P \leq 0.01,{ }^{\dagger \dagger} P \leq 0.001$, comparison of overall efficacy versus placebo

${ }^{\text {a }}$ Endpoint $=$ week 4 data, or previous recorded timepoint if week 4 not available

compared with placebo at week $2(P=0.003)$ and endpoint $(P=0.029$; Table 3$)$.

The proportion of patients in the prucalopride groups rating their treatment as extremely effective or quite a bit effective was higher than placebo at each timepoint. Overall the efficacy of treatment was rated significantly higher compared with placebo for prucalopride $4 \mathrm{mg}$ at week $2(P<0.001)$ and week $4(P=0.005$; Table 3$)$. Prucalopride treatment increased the percentage of stools with normal consistency and decreased the percentage of hardness of stools (data not shown).

Symptoms of constipation, as rated by the PAC-SYM questionnaire, improved more in treated patients compared with placebo (NS). Compared with placebo, almost as many patients in the $2 \mathrm{mg}$ group as in the $4 \mathrm{mg}$ group improved by $\geq 1$ point from baseline on the PAC-SYM total score (Fig. 3; $22.8 \%$ and $25.0 \%$, respectively, versus

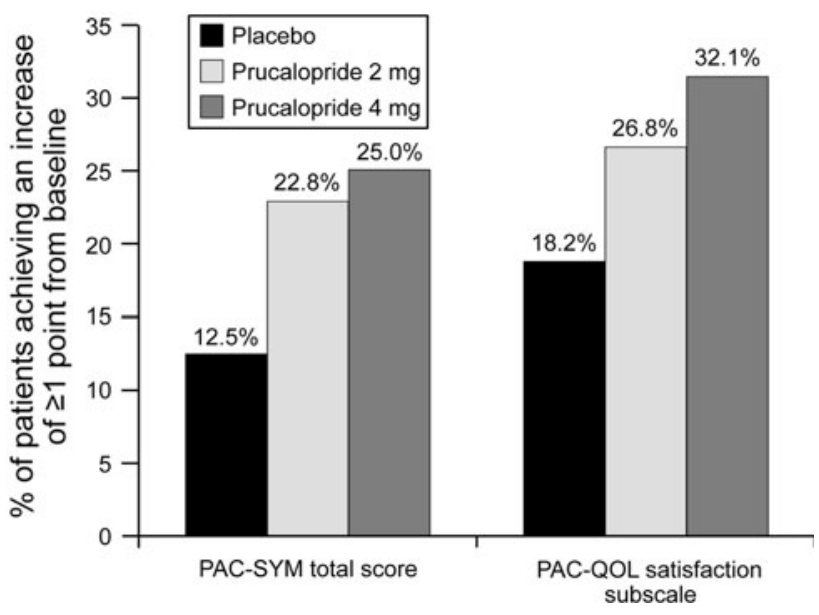

Fig. 3 Percentage of patients achieving improvement of $\geq 1$ point on the PAC-SYM questionnaire and PAC-QOL satisfaction subscale after 4 weeks of treatment. Proportion of patients with an improvement of $\geq 1$ point (out of 4 ) in PAC-SYM total score and PAC-QOL satisfaction subscale score at week 4 (or endpoint)

$12.5 \%)$. Stool and rectal symptoms tended to improve the most with prucalopride.

The mean change from baseline in the PAC-QOL total score and the satisfaction subscale score at week 4 was greater in treated patients compared with placebo; however, this did not reach statistical significance. A nonsignificant but dose-related trend was also seen in the proportion of patients improving by $\geq 1$ point on the PACQOL satisfaction subscale (Fig. 3).

Regarding laxative use, there was a decrease in the mean number of laxative tablets (Dulcolax ${ }^{\circledR}$, bisacodyl) in all groups, including prucalopride. This decrease was significantly greater in both prucalopride groups compared with placebo $[P=0.035$ (prucalopride $2 \mathrm{mg}$ ); $P=0.005$ (prucalopride $4 \mathrm{mg}$ )] at week 1 (Table 4 ).

Safety

All 196 randomized patients who took at least one dose of double-blind medication were included in the safety analysis.

\section{Adverse Events}

The incidence of treatment-emergent AEs was $48.5 \%$ with placebo (32/66), 57.6\% with prucalopride $2 \mathrm{mg}$ (38/66), and $50.0 \%$ with prucalopride $4 \mathrm{mg}(32 / 64)$.

The most frequently reported AEs were related to the GI system: abdominal pain and nausea. Abdominal pain was more frequently reported in the prucalopride $4 \mathrm{mg}$ group $(16 / 64,25.0 \%)$ compared with the prucalopride $2 \mathrm{mg}$ group $(8 / 66,12.1 \%)$ and placebo $(6 / 66,9.1 \%)$. In the body as a whole, pain was the most frequently reported $\mathrm{AE}$ 
Table 4 Average Dulcolax ${ }^{\circledR}$ (bisacodyl) tablets per week

\begin{tabular}{|c|c|c|c|c|c|c|c|c|c|}
\hline \multirow[t]{2}{*}{ Timepoint } & \multicolumn{3}{|c|}{ Placebo } & \multicolumn{3}{|c|}{ Prucalopride $2 \mathrm{mg}$} & \multicolumn{3}{|c|}{ Prucalopride $4 \mathrm{mg}$} \\
\hline & $n$ & Mean & Mean change & $n$ & Mean & Mean change & $n$ & Mean & Mean change \\
\hline Baseline & 63 & 4.6 & - & 64 & 4.2 & - & 62 & 4.1 & - \\
\hline Week 1 & 64 & 3.2 & -1.3 & 64 & 1.9 & $-2.3 *$ & 60 & 1.6 & $-2.5 * *$ \\
\hline Weeks $1-4$ & 60 & 2.9 & -1.4 & 61 & 1.9 & -2.4 & 58 & 2.2 & -2.2 \\
\hline
\end{tabular}

$* P \leq 0.05 ; * * P \leq 0.01$ versus placebo

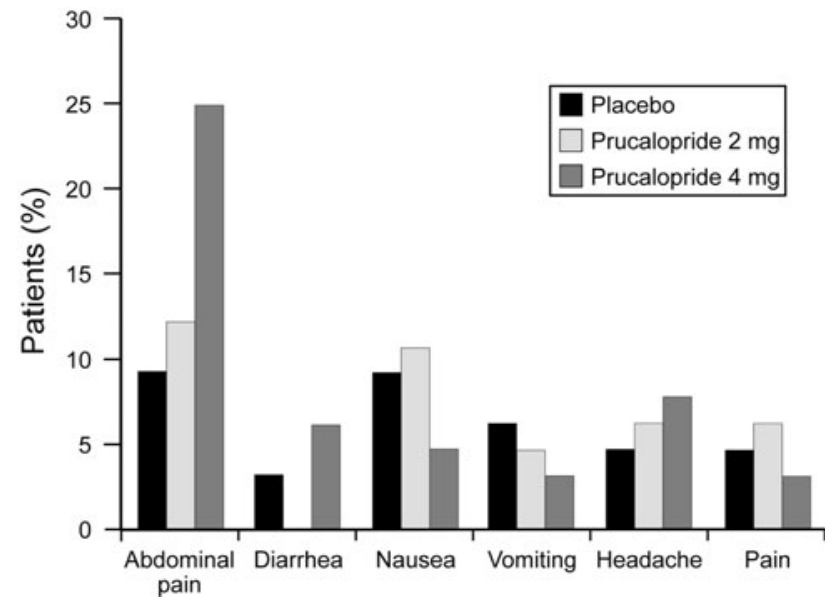

Fig. 4 Treatment-emergent adverse events reported by $\geq 5 \%$ of patients in any group

[prucalopride $2 \mathrm{mg}, 4 / 66$ (6.1\%); prucalopride $4 \mathrm{mg}, 2 / 64$ (3.1\%); placebo $3 / 66(4.5 \%)$ ]. Headache [prucalopride 2 $\mathrm{mg}$, 4/66 (6.1\%); prucalopride $4 \mathrm{mg}, 5 / 64$ (7.8\%); placebo $3 / 66(4.5 \%)]$ was the most common nervous system disorder (Fig. 4).

During the treatment phase, 38 patients reported severe AEs (13 on placebo, 11 on prucalopride $2 \mathrm{mg}, 14$ on prucalopride $4 \mathrm{mg}$ ). Of these, 25 patients had possibly drugrelated AEs ( 7 on placebo, 9 on prucalopride $2 \mathrm{mg}$, 9 on prucalopride $4 \mathrm{mg}$ ). The incidence of severe abdominal pain and headache was slightly higher in the prucalopride $4 \mathrm{mg}$ group than placebo, but there were no relevant differences between the groups for severity of other AEs and there was no clear dose relationship. Overall, the majority of AEs were considered as not likely to be related to the trial medication by the investigator. The AEs that were considered probably or very likely related to trial medication were mostly of GI origin.

A total of ten patients had serious AEs (four in each of the placebo and prucalopride $2 \mathrm{mg}$ groups, none in the prucalopride $4 \mathrm{mg}$ group during treatment; one in the placebo group during run-in and one in the prucalopride $4 \mathrm{mg}$ group after treatment). No deaths were reported.

There were 15 patients with treatment-emergent AEs leading to discontinuation of treatment: 7 with placebo, 3 with prucalopride $2 \mathrm{mg}$, and 5 with prucalopride $4 \mathrm{mg}$.
Abdominal pain was the most common reason for discontinuation in all treatment groups; other reasons for discontinuation were diverse and mostly unrelated to trial medication.

\section{Vital Signs, Laboratory, ECG Parameters}

No clinically relevant or consistent differences between treatment groups were observed for vital signs, laboratory or ECG parameters including heart rate, PR and QT intervals, QRS width, and corrected QT intervals $(\mathrm{QTcB}$ and QTcF; data not shown).

\section{Discussion}

Constipation is a common problem in patients regularly taking opioids for the treatment of chronic pain [3]. While laxatives are commonly recommended and prescribed to prevent OIC, no randomized controlled trials of laxatives for OIC have been reported. Laxatives may be effective in many patients with OIC, but they may not be effective or suitable in all patients. A recent survey in the USA among patients with constipation (including opioid-induced constipation) demonstrated that $47 \%$ of patients using laxatives were not completely satisfied with their treatment, mainly for reasons of efficacy [30]. Osmotic laxatives can be unpalatable [31], while bulk-forming laxatives require large water intakes and are therefore not ideal in elderly or immobile people.

Opiate antagonists are being investigated for the treatment of OIC and postoperative ileus. Currently in the UK and Europe, Relistor ${ }^{\circledR}$ (methylnaltrexone bromide) has been approved for the treatment of OIC in patients with advanced illness. Methylnaltrexone bromide, which is administered by injection only, improves the 4-h laxation response versus placebo, and is generally well tolerated, although serious AEs have been reported [32]. Addition of oral naloxone to oxycodone has also been shown to improve bowel function with no reduction in analgesic efficacy [33, 34], and use of alvimopan, a peripherally acting opioid antagonist, is also promising in early-phase studies in OIC [35], although this agent currently only has 
limited approval for short-term hospital use in postoperative ileus.

Prucalopride is the first selective serotonin $5-\mathrm{HT}_{4}$ receptor agonist that has been shown to be effective in patients with chronic constipation [14, 18, 19, 21, 23, 36-38]. In this phase II study of patients with OIC, prucalopride was effective during the first week of treatment with a relatively stable effect thereafter. Over the 4 weeks of treatment, $40 \%$ of patients taking $4 \mathrm{mg}$ prucalopride achieved the primary efficacy endpoint of an increase of $\geq 1$ SCBM from baseline, and half of patients taking $4 \mathrm{mg}$ achieved this endpoint at week $1(P \leq 0.05$ versus placebo). There was a corresponding significantly greater decrease in laxative use in the prucalopride groups than in the placebo group.

In the present study, prucalopride-treated patients had also improvements in a range of additional outcomes, including symptoms and QOL. Constipation is not just related to frequency of $\mathrm{BM}$, but also to symptoms, which together impact patients' functioning and well-being, and result in dissatisfaction with bowel function and ineffective treatments. More than $70 \%$ of constipated patients refer to the discomfort of hard stools, straining, bloating, abdominal discomfort, and feelings of incomplete evacuation as being severe [30]. It has been suggested therefore that treatment of constipation should have an impact on "at least several" of the attributes that are rated as most important by patients, including relief of constipation symptoms such as straining, hard or lumpy stools, infrequent stools, and improved quality of bowel movements [30]. There is little consistent evidence from double-blind, randomized controlled trials that traditional laxatives treat symptoms other than frequency of bowel movements in the long term [30, 39]. In the present study, patients taking prucalopride reported a larger improvement than did patients taking placebo in the severity of their constipation and the efficacy of treatment, as measured by the patientreported PAC-SYM and PAC-QOL questionnaires.

The effect size on bowel movements observed was comparable to those in larger trials of prucalopride in chronic constipation (non-opioid-induced). Of patients in the 2 and $4 \mathrm{mg}$ prucalopride groups, $36 \%$ and $40 \%$ (versus $23.4 \%$ of patients in the placebo group) had an improvement of $\geq 1$ SCBM per week, over the 4 weeks of treatment. This compares well with the prucalopride phase III studies, where $38-47 \%$ of patients improved by $\geq 1$ SCBM from baseline with $2 \mathrm{mg}$ prucalopride versus $21-28 \%$ with placebo [22-24]. Results with $4 \mathrm{mg}$ prucalopride in these phase III studies were similar to those with the $2 \mathrm{mg}$ dose. Although, in the current study, statistical significance was not reached for the primary and key secondary endpoints over the whole treatment period, this is most likely due to the smaller sample size in this study based on a power calculation estimating a $30 \%$ difference. However, a consistent trend was observed in prucalopride's effect on bowel movements, symptoms, and quality of life.

Consistent with the three phase III trials of prucalopride in chronic constipation, there was little difference in the frequency of AEs between placebo and prucalopride groups. The most frequent AEs reported in chronic constipation patients on prucalopride treatment were abdominal pain, nausea, diarrhea (related to the pharmacodynamic effect of the compound), and also headache. The incidence of these AEs in the OIC population of this trial was similar across all groups, except for abdominal pain, which was more commonly reported in the $4 \mathrm{mg}$ prucalopride group than the $2 \mathrm{mg}$ prucalopride and placebo groups, possibly related to the pharmacodynamic effect of prucalopride.

There was no difference between treatment groups in severity of AEs, except for a slightly higher incidence of severe abdominal pain in the $4 \mathrm{mg}$ prucalopride group versus placebo. There were no deaths during this trial, and serious AEs were considered to be doubtfully or not related to prucalopride treatment.

There were no clinically relevant differences in laboratory abnormalities between the groups, and there were no significant changes in vital signs from baseline in the prucalopride groups. There were also no cases of serious cardiac events with prucalopride. As prucalopride is not metabolized via CYP 3A4, no interactions with other medications are expected.

In general, the $2 \mathrm{mg}$ dose of prucalopride is effective in this population, but as there was little increase in AEs with the $4 \mathrm{mg}$ dose, it may be appropriate to increase to the $4 \mathrm{mg}$ dose in patients with more severe complaints or in whom the $2 \mathrm{mg}$ dose is well tolerated but not effective.

In this population with OIC, more patients in the 2 and $4 \mathrm{mg}$ prucalopride groups had an increase of $\geq 1$ SCBM per week from baseline compared with placebo over weeks 1-4, reaching significance at week 1 . Over the 4 weeks of treatment, improvements were seen in other efficacy parameters with 2 and $4 \mathrm{mg}$ prucalopride versus placebo, although not always reaching statistical significance.

The results in this smaller group were in line with those seen in larger pivotal studies of prucalopride in chronic constipation and suggest improved bowel movement frequency, reduction of symptoms, and improvement of patients' quality of life and satisfaction.

In addition, prucalopride was safe and well tolerated in this population with OIC.

Acknowledgments Medical writing support in the development of this manuscript was funded by Movetis N.V.

Disclosures The research fellowship of Dr. C.E.J. Sloots was partly sponsored by Janssen-Cilag. The study reported here was sponsored by Janssen-Cilag. 
Open Access This article is distributed under the terms of the Creative Commons Attribution Noncommercial License which permits any noncommercial use, distribution, and reproduction in any medium, provided the original author(s) and source are credited.

\section{References}

1. IMS Health National Prescription Audit, 2006.

2. IMS Health MIDAS database, 2005.

3. Panchal SJ, Muller-Schwefe P, Wurzelmann JI. Opioid-induced bowel dysfunction: prevalence, pathophysiology and burden. Int J Clin Pract. 2007;61:1181-1187.

4. Bell TJ, Panchal SJ, Miaskowski C, Bolge SC, Milanova T, Williamson R. The prevalence, severity and impact of opioidinduced bowel dysfunction: results of a US and European Patient Survey (PROBE 1). Pain Med. 2009;10:35-42.

5. de Luca A, Coupar IM. Insights into opioid action in the intestinal tract. Pharmacol Ther. 1996;69:103-115.

6. Wood JD, Galligan JJ. Function of opioids in the enteric nervous system. Neurogastroenterol Motil. 2004;16:17-28.

7. Holzer P. Treatment of opioid-induced gut dysfunction. Expert Opin Investig Drugs. 2007;16:181-194.

8. Mehendale SR, Yuan CS. Opioid-induced gastrointestinal dysfunction. Dig Dis. 2006;24:105-112.

9. Moore RA, McQuay HJ. Prevalence of opioid adverse events in chronic non-malignant pain: systematic review of randomised trials of oral opioids. Arthritis Res Ther. 2005;7:R1046-R1051.

10. Pappagallo $M$. Incidence, prevalence, and management of opioid bowel dysfunction. Am J Surg. 2001;182:11S-18S.

11. Kalso E, Edwards JE, Moore RA, McQuay HJ. Opioids in chronic non-cancer pain: systematic review of efficacy and safety. Pain. 2004;112:372-380.

12. Allan L, Hays $\mathrm{H}$, Jensen $\mathrm{NH}$, et al. Randomised crossover trial of transdermal fentanyl and sustained release oral morphine for treating chronic non-cancer pain. BMJ. 2001;322:1154-1158.

13. Adler HF, Atkinson AJ, Ivy AC. Effect of morphine and dilaudid on the ileum and of morphine, dilaudid and atropine on the colon of man. Arch Intern Med. 1942;69:974-985.

14. Bouras EP, Camilleri M, Burton DD, McKinzie S. Selective stimulation of colonic transit by the benzofuran 5HT4 agonist, prucalopride, in healthy humans. Gut. 1999;44:682-686.

15. De Schryver AM, Andriesse GI, Samsom M, Smout AJ, Gooszen HG, Akkermans LM. The effects of the specific 5HT(4) receptor agonist, prucalopride, on colonic motility in healthy volunteers. Aliment Pharmacol Ther. 2002;16:603-612.

16. de Maeyer JH, Lefebvre RA, Schuurkes JA. 5-HT (4) receptor agonists: Similar but not the same. Neurogastroenterol Motil. 2008;20:99-112.

17. Briejer MR, Prins NH, Schuurkes JA. Effects of the enterokinetic prucalopride (R093877) on colonic motility in fasted dogs. Neurogastroenterol Motil. 2001;13:465-472.

18. Bouras EP, Camilleri M, Burton DD, Thomforde G, McKinzie S, Zinsmeister AR. Prucalopride accelerates gastrointestinal and colonic transit in patients with constipation without a rectal evacuation disorder. Gastroenterology. 2001;120:354-360.

19. Coremans G, Kerstens R, De Pauw M, Stevens M. Prucalopride is effective in patients with severe chronic constipation in whom laxatives fail to provide adequate relief. Results of a doubleblind, placebo-controlled clinical trial. Digestion. 2003;67:82-89.

20. Emmanuel AV, Kamm MA, Roy AJ, Antonelli K. Effect of a novel prokinetic drug, R093877, on gastrointestinal transit in healthy volunteers. Gut. 1998;42:511-516.
21. Emmanuel AV, Roy AJ, Nicholls TJ, Kamm MA. Prucalopride, a systemic enterokinetic, for the treatment of constipation. Aliment Pharmacol Ther. 2002;16:1347-1356.

22. Quigley EM, Vandeplassche L, Kerstens R, Ausma J. Clinical trial: the efficacy, impact on quality of life, and safety and tolerability of prucalopride in severe chronic constipation-a 12-week, randomized, double-blind, placebo-controlled study. Aliment Pharmacol Ther. 2009;29:315-328.

23. Camilleri M, Kerstens R, Rykx A, Vandeplassche L. A placebocontrolled trial of prucalopride for severe chronic constipation. N Engl J Med. 2008;358:2344-2354.

24. Tack J, Van Outryve MV, Beyens G, Kerstens R, Vandeplassche L. Effect of prucalopride (RESOLOR) in the treatment of severe chronic constipation in patients dissatisfied with laxatives. Gut. 2009;58:357-365.

25. Van Outryve MV, Beyens G, Kerstens R, Vandeplassche L. Long-term follow up study of oral prucalopride (Resolar) administered to patients with chronic constipation. Gastroenterology. 2008;134:A-A547.

26. Mueller-Lissner SA, Rykx A, Kerstens R, Vandeplassche L. Randomized double-blind placebo-controlled trial to evaluate efficacy and safety of prucalopride (Resolor $\left.{ }^{\circledR}\right)$ in elderly patients with chronic constipation. Gastroenterology. 2008;134:A-A157. [Abstract no 1052].

27. Frank L, Kleinman L, Farup C, Taylor L, Miner P Jr. Psychometric validation of a constipation symptom assessment questionnaire. Scand J Gastroenterol. 1999;34:870-877.

28. Slappendel R, Simpson K, Dubois D, Keininger DL. Validation of the PAC-SYM questionnaire for opioid-induced constipation in patients with chronic low back pain. Eur J Pain. 2006;10:209217.

29. Marquis P, De La Loge C, Dubois D, McDermott A, Chassany O. Development and validation of the Patient Assessment of Constipation Quality of Life questionnaire. Scand J Gastroenterol. 2005;40:540-551.

30. Johanson J, Kralstein J. Chronic constipation: a survey of the patient perspective. Aliment Pharmacol Ther. 2007;25:599-608.

31. Voskuijl W, de Lorijn F, Verwijs W, et al. PEG 3350 (Transipeg) versus lactulose in the treatment of childhood functional constipation: a double blind, randomised, controlled, multicentre trial. Gut. 2004;53:1590-1594.

32. Slatkin N, Thomas J, Lipman AG, et al. Methylnaltrexone for treatment of opioid-induced constipation in advanced illness patients. J Support Oncol. 2009;7:39-46.

33. Meissner W, Leyendecker P, Mueller-Lissner S, et al. A randomised controlled trial with prolonged-release oral oxycodone and naloxone to prevent and reverse opioid-induced constipation. Eur J Pain. 2009;13:56-64.

34. Simpson K, Leyendecker P, Hopp M, et al. Fixed-ratio combination oxycodone/naloxone compared with oxycodone alone for the relief of opioid-induced constipation in moderate-to-severe noncancer pain. Curr Med Res Opin. 2008;24:3503-3512.

35. Webster L, Jansen JP, Peppin J, et al. Alvimopan, a peripherally acting mu-opioid receptor (PAM-OR) antagonist for the treatment of opioid-induced bowel dysfunction: results from a randomized, double-blind, placebo-controlled, dose-finding study in subjects taking opioids for chronic non-cancer pain. Pain. 2008; 137:428-440.

36. Sloots CE, Poen AC, Kerstens R, et al. Effects of prucalopride on colonic transit, anorectal function and bowel habits in patients with chronic constipation. Aliment Pharmacol Ther. 2002;16: 759-767.

37. Camilleri M, Specht Gryp R, Kerstens R, Vanderplassche L. Efficacy of 12-week treatment with prucalopride (Resolor) in patients with chronic constipation: combined results of three 
identical randomized, double-blind, placebo controlled phase III trials. Gastroenterology. 2008;134:A-A548.

38. Tack J, Ausma J, Kerstens R, Vanderplassche L. Safety and tolerability of prucalopride (Resolor) in patients with chronic constipation: pooled data from three pivotal phase III studies. Gastroenterology. 2008;134:25-530.

39. Johnson D. Treating chronic constipation: how should we interpret the recommendations? Clin Drug Investig. 2006;26:547-557. 